REVISTA IBEROAMERICANA. Vol. LXII, Núm. 174, Enero-Marzo 1996; 241-245

\title{
TRES LECTURAS SOBRE MANUEL PUIG
}

\author{
POR \\ ANDREA YANNUZZI \\ University of Pittsburgh
}

PAMELA BACARISSE: Impossible Choices. The Implications of the Cultural References in the Novels of Manuel Puig. Calgary and Cardiff: University of Calgary Press and University of Wales Press, 1993.

JONATHAN TITTLER: Manuel Puig. New York: Twayne Publishers, 1993.

JOSE AMÍCOLA: Manuel Puig y la tela que atrapa al lector. Buenos Aires: Grupo Editor Latinoamericano SRL, 1992.

Tres trabajos que nos invitan a desmenuzar la obra del escritor argentino Manuel Puig quien, nacido el 28 de diciembre de 1932 en General Villegas (provincia de Buenos Aires) y fallecido en Cuernavaca, México, el 22 de julio de 1990, dejara inconclusa su novena novela, Humedad relativa, 95\%, ambientada en la Argentina de los años cuarenta. Tres textos que, comparados entre sí, por momentos dialogan, se superponen y complementan. Tres instancias críticas entre las que intentaremos establecer una relación dinámica que nos permita dilucidar los abordajes que nos ofrecen.

El concepto central de cada estudio señala propuestas que proponen diferentes caminos pero encuentran puntos de contacto: Bacarisse enfatiza la ambivalencia de un discurso que carece de certezas y se asocia a la postmodernidad; en esta misma línea, Tittler admira a un narrador sin respuestas preconcebidas y la ausencia de presunción autorial. Amícola, en cambio, entiende que Puig construye su narrativa desde una dialéctica hegeliana que tiende a romper dicotomías para buscar y lograr una síntesis, conclusión que lo separa del escepticismo postmoderno con respecto a la posibilidad de construir totalidades.

Pamela Bacarisse sostiene que el amor (nunca la burla) que Puig profesara por los llamados géneros "menores" (popular culture) y la "cursilería" (81), de ninguna manera excluye la construcción artesanal y consciente de una intertextualidad que abraza y exalta también elementos del arte "culto" (Hight Art, high culture). Partiendo de esta premisa, Bacarisse realiza un recorrido por lo que ya desde el título nos anticipa como referencias culturales de amplio espectro. Examina tanto a los tangos y boleros como a las óperas que suenan en la obra de Puig, ya que ellas resultan piezas claves para agregar una nueva dimensión al entendimiento de las novelas. Explica que en The Buenos Aires Affair, por ejemplo, mientras Gladys contempla la posibilidad de suicidarse, se da cuenta de que ello equivaldría a perderse una ópera en la que siempre estuvo interesada y que resulta espejo 
de su vida: se trata nada menos que de Turandot (Puccini, 1926), en la que Liù, consumida por el amor no correspondido, resiste la tortura y se suicida (26). Asimismo, hay señalamientos sobre ballet, pintura, escultura, poesía, cine y literatura de muy diversa procedencia. Si nos imagináramos un cuadro de doble entrada (jugar con esta imagen debe ser producto de los complejos esquemas que elabora Amícola en su libro) tendríamos, por un lado, los mencionados elementos, y por el otro, el discurso de la incertidumbre postmoderna que atraviesa la galería de personajes de cada novela. Estos personajes son comparados y contrastados como vivas encarnaciones de mitos, arquetipos y estereotipos - "The Superior Man" (13), "Woman the Betrayer" (30), "Maternal Sacrifice" (37), "The Jews" (86), etc.- que se leen e interpretan desde las disciplinas que ellos mismos sugieren: psicoanálisis, astrología, feminismo y religión.

Con menciones a un variado marco teórico (Kristeva, Bajtín, Todorov, los formalistas rusos, Freud, Jung, Fromm, Marcuse) y en diálogo constante con las numerosas publicaciones sobre Puig, pero siempre desde los textos de este autor y para volver a ellos, Bacarisse opta por dividir su volumen de 172 páginas en capítulos temáticos. En ellos se enfatiza la ambivalencia del autor, cuya "preocupación central es preguntarse acerca de la felicidad" (14), "desde una comprensión no prescriptiva" (30) de la problemática de género, para establecer un contrapunto entre grupos de pertenencia y referencia "que sugieren peligro e infelicidad para ambos sexos" (30).

Ya desde el título, Impossible Choices alude al determinismo pesimista que transita la obra de Puig y coexiste con la nostalgia pequeño-burguesa que, atiborrada de sueños de felicidad y amor románticos, convive con la incapacidad de elegir. Esta incapacidad oscila, según Bacarisse, entre construcciones tales como machismo o mujeres emancipadas (46); deber o deseos (51), dependencia cultural o identidad nacional (98), libertad sexual o decadencia social (108). Los conflictos esbozan intereses imposibles de reconciliar, como en un tango, ya que el fatalismo cohabita con la esperanza y la fe como productos necesarios de la imaginación pues "para Puig la ilusión es condición esencial de la existencia" (89). Baste recordar el libro anterior de Bacarisse y lo sugerente de su denominación -The Necessary Dream: A Study of the Novels of Manuel Puig, 1988 - para ver en el presente estudio una continuación del anterior. Por último, esta crítica (se) cuestiona lo que podríamos denominar una "ideología de vida", tanto en Puig como en los personajes que se le hacen carne y melodramáticamente nos interrogan, nos confunden y nos dejan perplejos ante la violencia de sus contradicciones, los quiebres de sus respuestas inciertas y lo irremediable de sus maldiciones eternas.

Nota al pie: en las notas al pie (recordemos su importancia en El beso de la mujer araña) Bacarisse agrega comentarios jugosos, muchos de ellos pertenecientes a conversaciones con el autor y a otras fuentes que todavía no han sido publicadas.

Por su parte, Jonathan Tittler - quien considera que el uso de las notas al pie deriva de la familiaridad de Puig con los trabajos de Borges (51) - nos propone, a lo largo de 152 páginas, una cronología introductoria de las ocho novelas. En mucho coinciden sus argumentos con los de Bacarisse (a quien ocasionalmente citay responde), en particular con respecto a la idea de ambivalencia; pero Tittler remarca el pluralismo discursivo y el interjuego de voces, el dialogismo bajtiano como oposición a un narrador omnisciente autoritario, todo ello al servicio de una suerte de militancia que podríamos denominar 
"militancia de la diversidad", en tanto sustenta la relatividad polifónica de la verdad contra el absolutismo propio de las estructuras de poder. Dentro de esta tendencia "subversiva" (2), tal como Tittler lee a la noción misma de dialogismo, se inscribiría el uso que Puig hace de las teorías freudianas para crear una "insurrección contra el Padre del Psicoanálisis" (41): The Buenos Aires Affair representa un paso muy importante respecto de las dos primeras novelas pues el autor se atreve a desafiar las figuras ligadas a la autoridad, lo que implica, para Tittler, evaluar críticamente la figura misma de Freud.

Conjugando los opuestos bajtianos (poetics y prosaics), Tittler considera que la narrativa de Puig puede leerse como "poética de lo prosaico" y que, tal como en La traición de Rita Hayworth, se nutre del lenguaje cinematográfico al estilo Hollywood (24-37). En este sentido, al rediagramar la asociación y el espacio entre Valentín y Molina en El beso de la mujer araña, referentes comunes como celda y celuloide (cell y celluloid) adquieren nuevas connotaciones que combinan opresión y liberación, repetición y diferencia (57-58). Las funciones que se atribuyen a los silencios — pregnant silences (47) - se deslizan valientemente por terrenos siempre resbaladizos como los del capítulo VII, "Moral Correctness Reaffirmed" (103-122), pues se interpretan como equivalentes de un valor moral, de censura o autocensura (127). Agreguemos que Tittler entiende que la alta dosis de diálogos y oralidad, paradójicamente, indica una comunicación fallida, confluyendo con la especulación de Bacarisse que entrecruza el desencuentro y el fracaso en la búsqueda de felicidad como coordenadas de un escenario freudiano.

Detalle interesante: luego de enumerar los elementos postmodernos en Cae la noche tropical, Tittler descubre allí un lapsus y se pregunta si pertenece al autor, al narrador, o al personaje (Nidia); si corresponde a un error de imprenta o del editor (102) ... Asumir que ignoramos la respuesta empalma con un discurso no pretensioso que parece querer indicarnos lo erróneo de emitir juicios acerca de la intencionalidad del autor.

José Amícola nos ofrece en 293 páginas (es el trabajo más extenso) una amplia gama de reflexiones que van mucho más allá de la novela de Puig y del subtítulo que agrega en el interior del libro: "Estudio sobre El beso de la mujer araña en su relación con los procesos receptivos y con una continuidad literaria contestataria". De allí que, como evidente fruto de un estudio realizado durante años, presente la importancia de la "relación autor-obralector" (título de la cuarta parte) y los numerosos análisis de textos de Arlt y Cortázar, con quienes considera que Puig forma una "tríada", en tanto "realizadores de una literatura a contracorriente de las posturas oficiales y 'no afirmativa', en el sentido marcuseano de la palabra" (7).

Amícola respalda y fundamenta sus hipótesis haciendo disquisiciones teóricas que reúnen y diferencian a Bajtín, Jauss, Todorov y Habermas; Marcuse, Altman, Brown y Roszak; Horkheimer y Adorno; Link, Iser y Lukács; Freud, Jung y Lacan, entre otros. Divide su investigación en cuatro partes que mencionaremos porque sus encabezados devienen el mejor resumen de las temáticas que abarca: la primera introduce la obra de Puig, recorre cada novela y luego propone ir "Del folletín a la ciencia ficción" (45). La segunda parte anuncia el destino común de algunos elementos míticos (Orfeo, Narciso, Prometeo), estéticos e ideológicos: "Contra la unidimensionalidad del hombre"; "Las notas al pie y el narrador propiamente dicho"; "Dialogismo y carnavalización" y "Roles sexuales e ideología fascista" (67-138). La tercera, de sólo un capítulo - "El hombre político en las obras de 
Puig" (139-158) — es quizás la más vehemente, puesto que expresa apasionadas opiniones personales. En ella asocia política y sexualidad, analiza la influencia del feminismo norteamericano e interpreta al peronismo y la guerilla de los años setenta como incapaces de producir una contracultura nacional, mientras que, por el contrario, Puig sí propondría con su obra "una lucha guerrillera del escritor" (156). La última y cuarta parte se dedica a la teoría de la recepción como reflexión histórica e incluye (además de una breve biografia del autor, bibliografia sobre su obra y listado de sus principales entrevistas) la transcripción inédita del encuentro de Manuel Puig con estudiantes alemanes, organizado por el mismo Amícola y el profesor Manfred Engelbert en la Universidad de Göttingen, Alemania, en 1981. El diseño de complejos esquemas sugiere el intento de ilustrar y reforzar los postulados que ya se enuncian a lo largo del texto.

Amícola, como Tittler, enfatiza la ausencia de un narrador omnisciente y la visualización de la prosa a modo de guión cinematográfico (49). Cree, además, que una prueba de la invalidez de los postulados de MacLuhan subyace precisamente en El beso de la mujer araña, "donde IMAGEN Y LETRA ESCRITA se prestan mutuo apoyo ... [y] la FORMA ES EL CONTENIDO" (95). Considera que las notas al pie, insertas por el narrador oculto como recurso y material a la vez, reproducen la ambivalencia del autor (97)-noción central en el análisis de Bacarisse que retoma Titler, ambivalencia que, según Amícola, garantiza el pasaje a una dialéctica que busca la fusión hegeliana de los contrarios: "Así, por ello, la oposición entre homosexualidad y heterosexualidad se resuelve por la toma de partido en favor de una bisexualidad, como connatural del ser humano. La forma del contenido y de la expresión en la novela se sintetizan, justamente, en el beso que sirve de culminación al diálogo dialéctico de Molina y Valentín" (225). Se revela una concepción marcuseana que defiende al disidente sexual elevándolo a la categoría de revolucionario: "Molina muere, pues, no como cree Valentín - quien conoce una parte de la historia- como heroína de cine, sino como HOMOSEXUAL HEROICO ... La condición de Molina se torna, entonces, representativa de todas las sumisiones. Los elementos ideológicos han servido ahora para combatir la ideología" (227).

Dos datos importantes: a) Amícola teje una tela de insights y reflexiones que atrapan. b) Haciéndose eco de Josefina Ludmer, reclama justo reconocimiento para la figura del gran teorizador argentino Oscar Masotta, cuyo pensamiento habría influenciado a Puig. Amícola brinda un destacado espacio a los conceptos de Masotta, quien ya por 1967 concebía a la obra de arte como "híbrido", además de ser descubridor y difusor de Lacan en la Argentina, articular el pensamiento psicoanalítico con el marxista, rescatar el arte de masas y superar e integrar la línea de pensamiento sartreana que se imponía en la década anterior (206-210).

Digamos, para finalizar, que los lectores podrán acceder al análisis (y psicoanálisis) que Bacarisse hace de los personajes de las novelas, desde referentes culturales diversos y para probar el eclecticismo del autor desde su narrativa. Tittler realiza un recorrido lineal que exalta las encarnaciones de un discurso no autoritario, siempre abierto. Amícola elabora un compendio teórico en el que incluye su visión sobre la obra de Puig, a quien sitúa dentro de una estructura literaria mucho más amplia, en diálogo y continuidad con Arlt y Cortázar, separándolo de Borges.

En suma, la exploración de una ideología de vida como militancia de la diversidad, y en síntesis, la dialéctica literaria de contrarios que se reúnen. Tres trabajos que merecen 
nuestra consideración, tres lecturas críticas que se complementan, tres homenajes que, desde distintos ángulos pero similar estima, celebran el talento de Manuel Puig. 
